\title{
REVIEW
}

\section{Sex hormones, obesity and type 2 diabetes: is there a link?}

\author{
Alessandra Gambineri and Carla Pelusi \\ Endocrinology Unit, Department of Medical and Surgical Sciences, St Orsola-Malpighi Hospital, Alma Mater University of Bologna, Bologna, Italy
}

Correspondence should be addressed to A Gambineri: alessandra.gambiner3@unibo.it

\begin{abstract}
An imbalance in sex hormones has an important impact on type 2 diabetes (T2DM) mainly through the involvement of visceral adipose tissue. Androgens have an interesting sex-dimorphic association with T2DM, since hyperandrogenism in females and hypogonadism in males are risk factors for T2DM. Thus, treatments aimed at correcting hyperandrogenism in females and hypogonadism in males may prevent the development of T2DM or help in its treatment.
\end{abstract}

\section{Role of sex and gender on the development of type 2 diabetes}

There is increasing evidence that sex and gender differences influence the epidemiology, pathophysiology, treatment and outcomes of many diseases, including type 2 diabetes (T2DM) (1). The term sex is used to primarily indicate biological differences and the term gender predominantly describes the psychosocial differences between sexes. Sex differences between women and men include differences in sex hormones and their effects on organ systems. Gender differences arise from sociocultural processes and include different forms of nutrition, life styles or stress or attitudes toward treatments and prevention of diseases. Sex and gender differences are equally important in terms of development, awareness, presentation, diagnosis and therapy, as well as the prevention of T2DM, influencing each other, above all through the impact on obesity. There is a general agreement that obesity is the major risk factor for T2DM in both sexes, as supported by the data of the prevalence patterns of T2DM across regions which resemble those of obesity (2).

This review focuses on the link between sex hormones and T2DM through the impact that a sex hormone imbalance has on metabolic tissues, particularly on adipose tissue. The sexual dimorphism of androgens in the pathophysiology of T2DM is emphasized.

\section{Sex hormone differences between the sexes}

Males and females produce the same steroid hormones in a similar way. Regarding androgens, in both sexes, there are different synthesis pathways; a classic pathway where testosterone is synthesized directly in testicular Leydig cells in men and ovarian theca cells in women. Androgens are parallel produced from $\Delta 5$ - and $\Delta 4$-precursors, and therefore, converted into peripheral target tissues to the more potent androgen $5 \alpha$-dihydrotestosterone (DHT) by $5 \alpha$-reductase enzyme (3). However, it is also possible that testosterone is locally synthesized at the level of peripheral organs. For example, at the level of the adipose tissue, androstenedione (A4) is converted to testosterone by $17 \beta$-hydroxysteroid dehydrogenase type 5 (17 $\beta$-HSD5) and testosterone may be further activated to DHT by the type 1 isoform of $5 \alpha$-reductase. In addition, there are several alternative pathways to DHT synthesis, the backdoor pathway and alternate $5 \alpha$-dione pathway, which directly synthesize DHT from circulating androgen precursors in peripheral tissues bypassing the conventional intermediate testosterone (3). There is also an 11-oxygenated adrenal androgen pathway which converts A4 to 11ß-hydroxyandrostenedione (11OHA4) and testosterone to 11-keto-testosterone $(11 \mathrm{KT})$ and 11-keto-dihydrotestosterone (11KDHT) by 
adrenal 11 -hydroxylase (CYP11B1) activity. These are active 11-oxygenated androgens (3). In particular, 11KT and $11 \mathrm{KDHT}$ are able to activate the human androgen receptor (AR) with the same potency as testosterone and DHT. A4 and testosterone can be converted to the estrogens estrone (E1) and estradiol (E2), respectively, by aromatase (CYP19A1), which has been found in the ovary and testis as well as in many extragonadal tissues, including the brain, prostate gland, breast, bone, muscle, liver and adipose tissue.

The fact that both sexes make the same steroid hormones in a similar way means that physiological differences are necessarily quantitative in terms of (i) how much androgen is made, and (ii) what percentage of that quantity is converted into estrogen. If we focus on testosterone and E2, the two most potent representatives of their classes and the principal hormones synthesized in the gonads, two dramatic differences are evident. The testis makes approximately $7000 \mu \mathrm{g}$ of testosterone per day and converts one quarter of 1\% into E2, whereas the ovary makes only $300 \mu \mathrm{g}$ of testosterone per day, but fully converts half of it into E2. Thus, men make at least 20 times as much testosterone as women do; however, the percentage of testosterone that is converted into E2 in a woman is 200 times that in a man. In both sexes testosterone induces the estrogen sulfotransferase (EST), which inactivates E2 in E2 sulfate (E2-S); therefore, the higher the levels of testosterone, the higher the inactivation of E2 in E2 sulfate, thus contributing to the quantitative differences in sex steroids between the sexes (4).

However, there is also a qualitative difference between the sexes that depends on the production site of E2. In healthy premenopausal women, E2 is mainly produced by the ovaries and functions as a circulating hormone that acts on distant target tissues. In men and postmenopausal women, E2 does not function as a circulating hormone; rather, it is synthesized mainly in extragonadal sites and acts as a paracrine and intracrine factor (4).

Part of the sex hormone differences between the sexes also depends on the sex hormone-binding globulin (SHBG), which regulates the biological effect of sex steroids (5). Androgens and estrogens are transported in the blood by proteins, particularly SHBG and albumin which regulate the access of steroid hormones to their target cells. These proteins have different ligand affinities: albumin binds the sex hormones indistinctly and with a low affinity, whereas SHBG binds the sex hormones with a high affinity but the affinity to testosterone is twice that of $\mathrm{E} 2$ and distinct between sexes. In addition, in females, the amount of testosterone that is bound to SHBG is significantly higher than that in males (77 vs 53\%). Therefore, changes in the level of SHBG have a greater effect on the free testosterone level (and thus on its biological expression) than on the corresponding free E2 level, and this is particularly evident in the free testosterone level of females with respect to males. Thus, the serum transport of androgens and estrogens contributes to sex-based differences by regulating the relative free hormone levels available to target tissues. Main sex hormone differences between the sexes are summarized in Table 1.

\section{Sex-dimorphic association between androgens and type 2 diabetes results from clinical studies}

The sex-dimorphic association between testosterone and T2DM, which is consistently observed across racial and ethnic groups, is particularly evident in clinical studies (6). There are many cross-sectional population-based studies that demonstrate that lower levels of testosterone in men and higher levels of testosterone in women are associated with T2DM, while lower levels of SHBG are associated with T2DM particularly in females (7). Some prospective population-based studies thus indicate that endogenous testosterone may differentially influence the risk of T2DM in men and women. Reduced testosterone levels (both total and free) in men are in fact associated with a higher risk of T2DM, whereas higher testosterone levels (both total and free) as well as lower levels of SHBG in females are associated with a higher risk of T2DM (8).

Interestingly, prospective studies performed on men demonstrate that the inverse relationship between testosterone and the risk of diabetes mainly depend on the abdominal obesity phenotype. In fact, after adjustment for waist circumference, this relationship drastically attenuates (9). In females, the risk of T2DM increases with the aggravation of hyperandrogenism (10) and becomes particularly evident in hyperandrogenic disorders, such as polycystic ovary syndrome (PCOS).

PCOS is the most common hyperandrogenic disorder in women with a prevalence in European women in the fertile age of around 6-8\% (11). Observational crosssectional studies performed on PCOS and included by Moran et al. in a meta-analysis estimate that the odds of T2DM are four times as high for women with PCOS compared with controls (12). A subgroup matched https://ec.bioscientifica.com https://doi.org/10.1530/EC-18-0450 (c) 2019 The authors Published by Bioscientifica Ltd
This work is licensed under a Creative Commons Attribution-NonCommercial-NoDerivatives 4.0 International License. 
Table 1 Main sex hormone differences between the sexes.

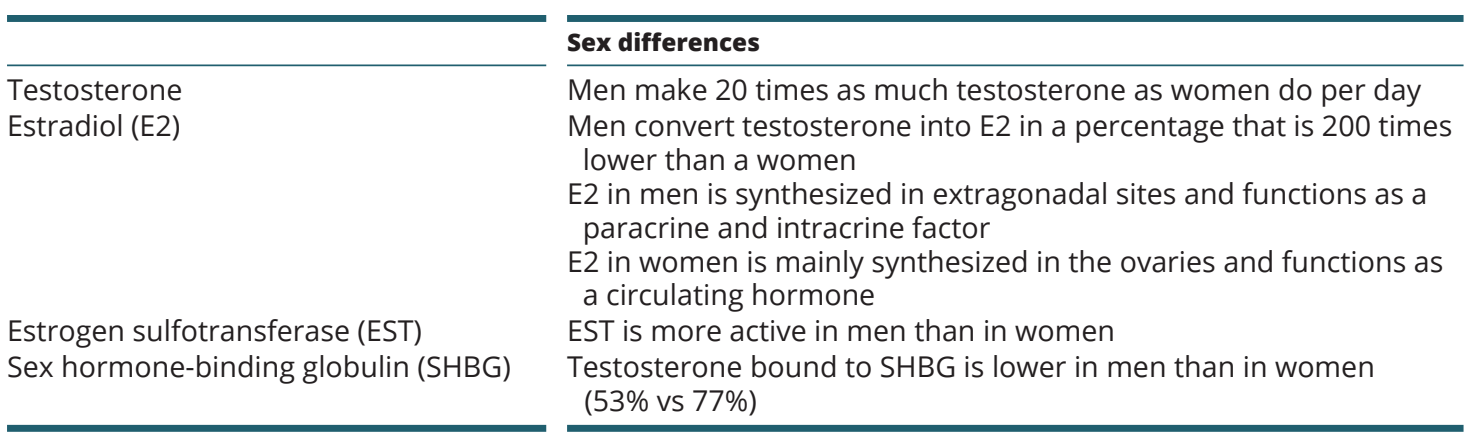

\begin{tabular}{c}
\hline References \\
\hline$(3)$ \\
$(3,4)$ \\
\\
\\
$(4)$ \\
$(5)$
\end{tabular}

for BMI confirmed that the odds of T2DM were more than two to eight times as high for women with PCOS compared with BMI-matched controls, thus supporting the inference that T2DM is associated with PCOS independently and additively to obesity (12). Some large prospective studies have demonstrated that the incidence of T2DM in women with PCOS is very high, thus confirming that PCOS is a risk factor for T2DM $(13,14)$. In a prospective study in Italy, the incidence rate of T2DM was found to be 1.05 per 100 person-years, which is 2.6 times higher than that in the general age-matched national female population (15). A higher BMI and lower SHBG have been proven to be independently associated with an increased risk of T2DM in this population and therefore predictive of the development of T2DM in women with PCOS (15). In addition, by stratifying incidence rates of T2DM by class of BMI, it was revealed that the absolute risk of diabetes increased steadily with BMI and was particularly high for a BMI over $30 \mathrm{~kg} / \mathrm{m}^{2}$ (2.02 per 100 person-years, for an incidence rate ratio equal to 4.44; $P<0.001$ vs non-obese PCOS women) (15). Accordingly, in a recent study from the United Kingdom performed on a large cohort of women extracted from the General Practice Research Database, a longitudinal, anonymized research database derived from nearly 600 primary-care practices in the United Kingdom, it was demonstrated that the risk of the development of T2DM was significantly increased in a lean subgroup of PCOS (hazard ratio-HR of 1.4 for $\mathrm{BMI}<25 \mathrm{~kg} / \mathrm{m}^{2}$ ). However, there was an increase in HR stratified by BMI, with the highest risk in the obese PCOS phenotype (16). Interestingly, in a prospective population-based cohort study, an increase in weight between the ages of 14 and 31 years was found which was significantly greater in women with PCOS developing T2DM than in women with PCOS and normal glucose tolerance. This thus supports the evidence that weight gain especially during early adulthood seems to be a crucial risk factor for the development of T2DM in PCOS (17). These data support the most widely accepted hypothesis that the increased risk of T2DM in PCOS is mainly related to the strong interaction between androgens, obesity and peripheral insulin resistance. Animal studies demonstrate that female rats that received the non-aromatizable androgen DHT by continuous administration at early puberty increased body weight, enlarged intra-abdominal fat and developed insulin resistance (18). Similarly, human studies performed on female-to-male transsexuals demonstrated that testosterone-ester administration at the dose of $250 \mathrm{mg}$ i.m. every 2 weeks produced a significant increase in visceral adipose tissue and a decrease in insulin sensitivity evaluated by the euglycemic-hyperinsulinemic clamp $(19,20)$.

Similar findings but with an inverse relationship have also been proposed in men. Approximately one-third of men with T2DM or metabolic syndrome showed subnormal total and free testosterone levels mainly associated with inappropriately low LH and FSH concentrations $(21,22)$. This condition has been recently defined as functional hypogonadism characterized by hormonal levels compatible with hypogonadotropic hypogonadism, a normal response of LH and FSH to GnRH stimulus, and no abnormal anatomical hypothalamic-pituitary-testicular axis. Although hypogonadotropic hypogonadism seems to be the dominant condition associated with T2DM patients, in the literature, a minimum percentage of diabetic subjects have also been reported to have low testosterone levels with high gonadotropin concentrations (21). In any case, irrespective of the biochemical form of hypogonadism associated with T2DM in men, that is, hyper- or hypogonadotropic, all the diabetic patients with low testosterone usually experience significant symptoms suggestive of hypogonadism, such as fatigability and erectile dysfunction.

The association between low testosterone levels and T2DM in men has been fully established and considered

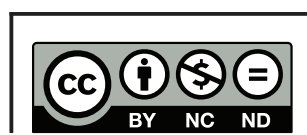

This work is licensed under a Creative Commons Attribution-NonCommercial-NoDerivatives 4.0 International License. 
bidirectional, although there is more literature supporting the influence of low testosterone on the development of T2DM. It has been estimated that low testosterone at baseline approximately doubles the odds of developing T2DM in men $(23,24)$. Moreover, a 2011 meta-analysis of 52 observational studies relating metabolic syndrome to determinants of testosterone status showed that men with the highest tertile of testosterone had a lower risk of metabolic syndrome than men with the lowest tertile of testosterone (RR estimate: 0.38, 95\% CI 0.28-0.50). In addition, those men with higher SHBG levels had a reduced risk of developing metabolic syndrome (RR estimate $=0.29,95 \%$ CI $0.21-0.41)$ (25). The possibility that male subjects with low testosterone levels are predisposed to T2DM has been confirmed by longitudinal studies in a meta-analysis with a median of follow-up of 10 years $(26)$.

On the other hand, several studies have shown that the duration and severity of hyperglycemia does not seem to be responsible for low testosterone levels in T2DM patients (27) but rather are adiposity and insulin resistance $(24,28,29)$. This is supported by the relatively rare cases of hypogonadotropic hypogonadism described in type 1 diabetic patients (30) and also by the well-established inverse relationship between total and free testosterone circulating levels with BMI $(24,31)$. In addition, the cytokines produced by the adipose tissue may contribute directly to the suppression of the hypothalamic pituitarygonadal axis $(32,33)$ and, therefore, to the development of hypogonadotropic hypogonadism. Accordingly, the association observed between testosterone or SHBG and glucose levels in hypogonadic men with T2DM was significantly attenuated after adjusting for adiposity (34).

Although obesity plays an important role in reducing testosterone levels in T2DM, some diabetic patients with a normal BMI may have hypogonadotropic hypogonadism (31), thus suggesting the direct key role of insulin resistance. Some animal and human studies have proven the inverse association between testosterone and insulin resistance $(35,36)$ as well as an increased risk of T2DM (37). Mice with a neuron-specific disruption of the insulin receptor gene (NIRKO mice) have been shown to develop peripheral insulin resistance, and a reduction in $\mathrm{LH}$ and testosterone concentrations. This thus suggests the important role of insulin receptor signaling in the brain for the maintenance of the functional integrity of the hypothalamic-pituitary-gonadal axis and of energy disposal (38).

To further support this association, studies conducted in patients with prostate cancer undergoing androgen deprivation therapy (ADT) have shown that lack of testosterone production is responsible for metabolic effects such as changes in body composition, insulin resistance and lipid profiles that worsen with time (39). In particular, ADT induces fat accumulation that, differently from what is observed in the metabolic syndrome, is mostly at subcutaneous levels and reduction of lean body mass. In addition, patients with ADT usually present an abnormal lipid profile and a worsening of insulin sensitivity with an increased risk of incident T2DM (HR 1.24; 95\% CI, 115-135; $P<0.05)$, myocardial infarction and sudden cardiac death $(40,41)$.

In conclusion, as shown in women, in men there is also a strong but opposite relationship between testosterone levels, obesity and insulin resistance, thus supporting interlinked causative mechanisms between male hypogonadism and T2DM.

\section{The similar role of androgens in metabolic target tissues in males and females how can the sex-dimorphic association be explained between androgens and type 2 diabetes?}

Androgens exert key effects on two metabolic target tissues - the adipose tissue and the skeletal muscle - in both men and women (3) (Fig. 1). At the level of the skeletal muscle, androgens enhance the differentiation of stem cells to myotubes, as well as skeletal muscle protein synthesis thus promoting muscular growth (3). In addition, androgens improve insulin sensitivity by interfering directly with insulin signaling as well as by enhancing GLUT4 expression and translocation to the plasma membrane (3). Finally, androgens stimulate lipid oxidation and glucose usage and mitochondrial function (3).

At the level of the adipose tissue, androgens impair adipogenesis by inhibiting the proliferation and differentiation of mesenchymal stem cells and preadipocytes (3). DHT and testosterone in fact have inhibitory effects on multipotent stem cell commitment to the preadipocyte lineage and adipocyte differentiation in both sexes. An impairment in adipocyte proliferation and differentiation may lead to adipocyte hypertrophy as a compensatory mechanism, which is driven by the accumulation of lipids in differentiated adipocytes. Hypertrophy in adipocytes induces adipocyte dysfunction. In fact, hypertrophic adipose tissue is insulin resistant produces a high amount of free fatty acids-FFA and induces macrophage recruitment and activation. Activated macrophages secrete

This work is licensed under a Creative Commons Attribution-NonCommercial-NoDerivatives 4.0 International License. 
EFFECT OF ANDROGENS

$\uparrow$ ADIPOCYTE HYPERTROPHY
$\downarrow$ INSULIN SENSITIVITY
$\downarrow$ LIPID STORAGE
$\uparrow$ LIPOLYSIS

$\uparrow$ PROTEIN SYNTHESIS

$\uparrow$ DIFFERENTIATION OF STEM CELLS TO MYOTUBES

$\uparrow$ INSULIN SENSITIVITY

$\uparrow$ GLUCOSE USAGE

$\uparrow$ LIPID OXIDATION
SITE OF ACTION
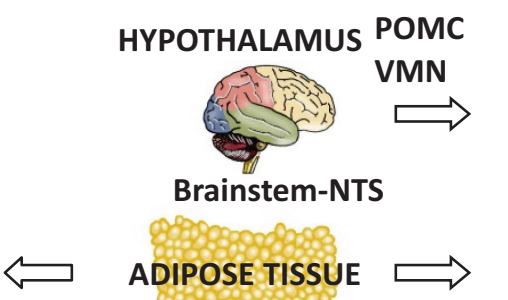

A
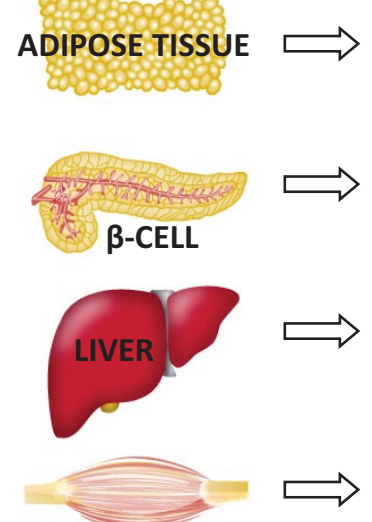

SKELETAL MUSCLE

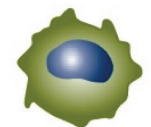

MACROPHAGES

\section{EFFECT OF ESTROGENS}

$\downarrow$ FOOD INTAKE

$\uparrow$ ENERGY EXPENDITURE

REGULATE BODY FAT DISTRIBUTION

$\downarrow$ WHITE ADIPOSE TISSUE

ACCUMULATION

$\downarrow$ LIPOLYSIS

PROTECT $\beta$-CELL AGAINST VARIOUS

INJURIES

$\uparrow$ GLUCOSE STIMULATED INSULIN

SYNTHESIS

MAINTAIN INSULIN ACTION

$\downarrow$ FATTY ACID UPTAKE

$\uparrow$ FATTY ACID OXIDATION

MAINTAIN INSULIN ACTION

$\downarrow$ TISSUE INFLAMMATION

$\uparrow$ PERIPHERAL INSULIN SENSITIVITY

Figure 1

Sex hormone effects on metabolic target tissues in both sexes.

proinflammatory cytokines, particularly TNF-alpha and IL-6, which worsen adipocyte insulin sensitivity leading to further FFA release and block preadipocyte recruitment, leading to even larger adipocytes, thus producing a vicious circle. Androgens also directly influence adipose insulin sensitivity (3). In particular, testosterone directly induces insulin resistance in subcutaneous adipocytes in vitro and inhibits insulin-stimulated glucose uptake by impairing the phosphorylation of protein kinase $\mathrm{C}$ via an androgen receptor-mediated mechanism. In addition, androgens decrease lipoprotein lipase, therefore decreasing lipid storage and increasing lipolysis (3).

It has been hypothesized that at sex-related physiological androgen levels, the net effect on myocytes predominates in both men and women, whereas at pathological androgen levels (hypogonadism in men and hyperandrogenism in women), the net effect on the adipose tissue drives the systemic phenotype and gives rise to metabolic diseases.

Interestingly, several rodent, sheep and primate models have recently demonstrated that androgens directly act on the central nervous system, influencing the metabolism in a sexually dimorphic manner also at physiological levels
(42). Androgens directly regulate the sympathetic nervous system output to white adipose tissue (WAT), and food intake, through the regulation of the orexigenic peptide proopiomelanocortin-POMC, central sensitivity to leptin and energy expenditure in a sexually dimorphic manner. In females, androgens increase the sympathetic output to WAT, increase food intake, produce leptin resistance and decrease energy expenditure, whereas they have the opposite effect in males. This central sexual dimorphic effect of androgens probably contributes to abdominal obesity, insulin resistance and T2DM in hyperandrogenic and hypogonadic conditions in females and males, respectively.

Role of estrogens in metabolic target tissues: a potential role in linking hypogonadism and type 2 diabetes in men

Estrogens are significantly and similarly involved in the regulation of different metabolic target tissues in both sexes (4) (Fig. 1). At the level of the adipose tissue, estrogens reduce WAT accumulation by lowering fatty acid uptake

This work is licensed under a Creative Commons Attribution-NonCommercial-NoDerivatives 4.0 International License. 
and lipogenesis, and they are able to decrease lipolysis through the inhibition of lipoprotein lipase activity, finally reducing adipocyte hypertrophy and ectopic lipid accumulation. At the level of the skeletal muscle, estrogens decrease the fatty acid uptake, increase fatty acid oxidation and increase catecholamine-stimulated lipolysis. In addition, estrogens maintain insulin action at the level of the skeletal muscle and the liver. Estrogens also protect pancreatic beta-cells against oxidative stress, amyloid polypeptide toxicity, lipotoxicity and apoptosis; and they also enhance glucose-stimulated insulin biosynthesis. Estrogens also act at the level of macrophages decreasing tissue inflammation and improving peripheral insulin sensitivity. In addition, estrogens act on the central nervous system in the hypothalamus, particularly at the level of arcuate-ARC nucleus, where they decrease food intake through both a direct effect and an effect mediated by leptin and neuropeptide-1-NPY. Estrogens, in fact, increase the sensitivity of ARC nucleus to leptin and decrease the sensitivity of ARC nucleus to NPY. Estrogens also act at the level of ventromedial neuronsVMN, thus reducing food intake, increasing energy expenditure through the stimulation of physical activity and thermogenesis and regulating body fat distribution; less central/intra-abdominal and more gluteal/femoral and subcutaneous depots. Finally, acting at the level of the nucleus tractus solitarious, estrogens reduce food intake.

Taking into account all these positive metabolic effects of estrogens, it can be hypothesized that the hypoestrogenic condition that characterizes hypogonadism in men may participate in producing and/or aggravating T2DM through its impact on triggering metabolic tissues, particularly the adipose tissue.

\section{The link between adiposity, particularly visceral adiposity, and type 2 diabetes}

Adipose tissue expandability is not unlimited and varies among individuals depending on both genetic and environmental factors. When adipose tissue expansion limits are reached, ectopic lipid accumulation develops, causing insulin resistance, inflammation in the peripheral tissues and also diabetes (43). This is particularly evident in visceral adipose tissue (VAT) for many reasons. VAT is less expandable than subcutaneous adipose tissue (SAT), which means VAT has less storage than SAT, with a consequent more ectopic fat accumulation. VAT is mostly located within the intraperitoneal cavity, draining directly to the liver through the portal circulation, thus facilitating the influence of its secretory products on the liver (44). VAT is also more vascular and innervated than SAT and is more sensitive to lipolysis as it has more beta3-adrenoceptors which mediate catecholamine-induced lipolysis. VAT contains more inflammatory and immune cells and is more insulin resistant than SAT. VAT has a higher expression of the 11beta-hydroxysteroid dehydrogenase type 1 enzyme, which locally activates inactive cortisone into active cortisol and has a higher density of glucocorticoid receptors than SAT. VAT is also more exposed to androgenic action because of a higher density of ARs and lower expression of aldo-keto reductase 1c enzymes, which are involved in androgen metabolism. Finally, VAT is less exposed to estrogenic action because of the lower density of estrogen receptors (44). Therefore, VAT is more exposed than SAT to a sex steroid imbalance in both females and males.

This thus supports the association between sex steroid dysfunctions (hyperandrogenism in females, and hypogonadism in males), visceral adiposity and T2DM in both sexes.

\section{Metabolic impact of antiandrogens in hyperandrogenic females}

In terms of hyperandrogenic females, at present there are few data to support the use of antiandrogens to prevent or treat T2DM. Moghetti et al. demonstrated that a few months of antiandrogen treatment in women affected by PCOS significantly increased the insulin sensitivity evaluated by an euglycemic-hyperinsulinemic clamp (45). Our group confirmed that 12 months of antiandrogen therapy in overweight/obese PCOS women improved insulin sensitivity and decreased VAT (46). We also demonstrated that PCOS women treated for a long-term period of time with third-generation oral contraceptives (OCs), which can be considered an antiandrogen therapy, compared to those untreated by OCs, maintained a stable body weight and their insulin resistance did not worsen, but by contrast the glucose tolerance improved. These results suggest that OCPs in PCOS combat the natural lifelong metabolic deterioration of the syndrome (47). Overall, these data suggest that antiandrogens could be used to prevent or to treat T2DM in PCOS; however, more studies are warranted to confirm these data.

\section{Metabolic impact of testosterone correction in hypogonadic men}

In hypogonadic men, supplementation of testosterone or drugs that promote an increase in endogenous I 
testosterone blood concentrations may be considered strategic therapies for T2DM. Several studies conducted in hypogonadal men with T2DM have demonstrated the beneficial effect of testosterone supplementation in reducing insulin resistance and diabetic chronic inflammation (48), in improving glycemic control (49) and in changing body composition $(50,51)$, whereas others showed no benefit $(52,53)$. In particular, the majority of trials (meta-analysis and randomized controlled trials) performed in hypogonadic dysmetabolic patients agree in revealing a more pronounced testosterone treatment effect on body composition rather than on glycemic control in which results are variables (54). The discrepancy between the studies reflects several issues: small sample size, differences in baseline metabolic characteristics such as glycated hemoglobin levels, degrees of insulin resistance and glycemic controls, different types of testosterone treatment used and finally the timing of testosterone administration. However, in a mouse model of highfat diet-induced T2DM without a diagnosis of gonadal dysfunction, testosterone supplementation was found to improve glucose homeostasis (55). Therefore, although the assumptions are in favor of possible beneficial effect of testosterone supplementation on glucose control and markers of metabolic syndrome, according to the recent endocrine society clinical practice guidelines, there is no enough adequate evidence to recommend testosterone treatment in diabetic hypogonadic men for only improving glycemic control (56).

A new class of drugs, selective estrogen receptor modulators, are now being administered in patients with functional hypogonadism, leading to an increase in androgen concentrations to physiological range, thus supporting their potential future use as an alternative option in this area (57). In particular, clomiphene citrate acting as an estrogen antagonist at the level of the pituitary gland induces the release of $\mathrm{LH}$ and FSH, which in turn drives the endogenous steroidogenic production in functional hypogonadic patients $(58,59)$. To date, only a few studies have evaluated the effect of clomiphene citrate on body composition and glucose metabolism, but all with promising results $(59,60)$. Our group found a positive effect of clomiphene citrate in ameliorating glucose and insulin levels in obese dysmetabolic patients with low testosterone levels (59), thus supporting their potential use in these types of subjects.

Although the above-mentioned findings strongly suggest that increasing androgen levels through testosterone supplementation or other treatments has a positive impact against T2DM in hypogonadic males, further clinical trials are still needed to confirm this scenario and to determine the appropriate approaches.

\section{Conclusions}

The model that explains the contribution of different factors to the development of T2DM attributes particularly major roles to obesity and visceral-abdominal fatness, providing that a genetic predisposition is present, and this is emphasized in the presence of a sex steroid imbalance. The sexual dimorphism of androgens in the pathophysiology of T2DM suggests that there are inequalities in both the preventive strategies and treatment between women and men and also highlights the potential use of a gender-specific medicine. Further studies are needed in this exciting area.

\section{Declaration of interest}

The authors declare that there is no conflict of interest that could be perceived as prejudicing the impartiality of this review.

\section{Funding}

This work did not receive any specific grant from any funding agency in the public, commercial or not-for-profit sector.

\section{References}

1 EUGenMed Cardiovascular Clinical Study Group, Regitz-Zagrosek V, Oertelt-Prigione S, Prescott E, Franconi F, Gerdts E, Foryst-Ludwig A, Maas AH, Kautzky-Willer A, Knappe-Wegner D, Kintscher U, et al. Gender in cardiovascular diseases: impact on clinical manifestations, management, and outcomes. European Heart Journal 201637 24-34. (https://doi.org/10.1093/eurheartj/ehv598)

2 Kautzky-Willer A, Harreiter J \& Pacini G. Sex and gender differences in risk, pathophysiology and complications of type 2 diabetes mellitus. Endocrine Reviews 201637 278-316. (https://doi. org/10.1210/er.2015-1137)

3 Schiffer L, Kempegowda P, Arlt W \& O’Reilly MW. Mechanisms in endocrinology: the sexually dimorphic role of androgens in human metabolic disease. European Journal of Endocrinology 2017177 R125-R143. (https://doi.org/10.1530/EJE-17-0124)

4 Mauvais-Jarvis F, Clegg DJ \& Hevener AL. The role of estrogens in control of energy balance and glucose homeostasis. Endocrine Reviews 201334 309-338. (https://doi.org/10.1210/er.2012-1055)

5 Vermeulen A, Verdonck L \& Kaufman JM. A critical evaluation of simple methods for the estimation of free testosterone in serum. Journal of Clinical Endocrinology and Metabolism 199984 3666-3672. (https://doi.org/10.1210/jcem.84.10.6079)

6 Dwyer AA \& Quinton R. The metabolic syndrome in central hypogonadotrophic hypogonadism. Frontiers of Hormone Research Home 201849 156-169. (https://doi.org/10.1159/000485998)

7 Ding EL, Song Y, Malik VS \& Liu S. Sex differences of endogenous sex hormones and risk of type 2 diabetes: a systematic review and meta-analysis. JAMA 2006295 1288-1299. (https://doi.org/10.1001/ jama.295.11.1288) 
8 Gyawali P, Martin SA, Heilbronn LK, Vincent AD, Taylor AW, Adams RJT, O'Loughlin PD \& Wittert GA. The role of sex hormonebinding globulin (SHBG), testosterone, and other sex steroids, on the development of type 2 diabetes in a cohort of community-dwelling middle-aged to elderly men. Acta Diabetologica 201855 861-872. (https://doi.org/10.1007/s00592-018-1163-6)

9 Grossmann M. Low testosterone in men with type 2 diabetes: significance and treatment. Journal of Clinical Endocrinology and Metabolism 201196 2341-2353. (https://doi.org/10.1210/ jc.2011-0118)

10 Fenske B, Kische H, Gross S, Wallaschofski H, Völzke H, Dörr M, Nauck M, Keevil BG, Brabant G \& Haring R. Endogenous androgens and sex hormone-binding globulin in women and risk of metabolic syndrome and type 2 diabetes. Journal of Clinical Endocrinology and Metabolism 2015100 4595-4603. (https://doi.org/10.1210/ jc.2015-2546)

11 Conway G, Dewailly D, Diamanti-Kandarakis E, Escobar-Morreale HF, Franks S, Gambineri A, Kelestimur F, Macut D, Micic D, Pasquali R, et al. The polycystic ovary syndrome: a position statement from the European Society of Endocrinology. European Journal of Endocrinology 2014171 P1-P29. (https://doi.org/10.1530/EJE-14-0253)

12 Moran LJ, Misso ML, Wild RA \& Norman RJ. Impaired glucose tolerance, type 2 diabetes and metabolic syndrome in polycystic ovary syndrome: a systematic review and meta-analysis. Human Reproduction Update 201016 347-363. (https://doi.org/10.1093/ humupd/dmq001)

13 Boudreaux MY, Talbott EO, Kip KE, Brooks MM \& Witchel SF. Risk of T2DM and impaired fasting glucose among PCOS subjects: results of an 8-year follow-up. Current Diabetes Reports 20066 77-83. (https:// doi.org/10.1007/s11892-006-0056-1)

14 Wang ET, Calderon-Margalit R, Cedars MI, Daviglus ML, Merkin SS, Schreiner PJ, Sternfeld B, Wellons M, Schwartz SM, Lewis CE, et al. Polycystic ovary syndrome and risk for long-term diabetes and dyslipidemia. Obstetrics and Gynecology 2011117 6-13. (https://doi. org/10.1097/AOG.0b013e31820209bb)

15 Gambineri A, Patton L, Altieri P, Pagotto U, Pizzi C, Manzoli L \& Pasquali R. Polycystic ovary syndrome is a risk factor for type 2 diabetes: results from a long-term prospective study. Diabetes 2012 61 2369-2374. (https://doi.org/10.2337/db11-1360)

16 Morgan CL, Jenkins-Jones S, Currie CJ \& Rees DA. Evaluation of adverse outcome in young women with polycystic ovary syndrome versus matched, reference controls: a retrospective, observational study. Journal of Clinical Endocrinology and Metabolism 201297 3251-3260. (https://doi.org/10.1210/jc.2012-1690)

17 Ollila MM, West S, Keinänen-Kiukaaniemi S, Jokelainen J, Auvinen J, Puukka K, Ruokonen A, Järvelin MR, Tapanainen JS, Franks S, et al. Overweight and obese but not normal weight women with PCOS are at increased risk of Type 2 diabetes mellitus-a prospective population-based cohort study. Human Reproduction 201732968. (https://doi.org/10.1093/humrep/dex030)

18 Mannerås L, Cajander S, Holmäng A, Seleskovic Z, Lystig T, Lönn M \& Stener-Victorin E. A new rat model exhibiting both ovarian and metabolic characteristics of polycystic ovary syndrome. Endocrinology 2007148 3781-3791. (https://doi.org/10.1210/en.2007-0168)

19 Elbers JM, Asscheman H, Seidell JC, Megens JA \& Gooren LJ. Longterm testosterone administration increases visceral fat in female to male transsexuals. Journal of Clinical Endocrinology and Metabolism 199782 2044-2047. (https://doi.org/10.1210/jcem.82.7.4078)

20 Elbers JM, Giltay EJ, Teerlink T, Scheffer PG, Asscheman H, Seidell JC \& Gooren LJ. Effects of sex steroids on components of the insulin resistance syndrome in transsexual subjects. Clinical Endocrinology 200358 562-571. (https://doi.org/10.1046/j.13652265.2003.01753.x)

21 Dandona P \& Dhindsa S. Update: Hypogonadotropic hypogonadism in type 2 diabetes and obesity. Journal of Clinical Endocrinology and Metabolism 201196 2643-2651. (https://doi.org/10.1210/jc.2010-2724)
22 Barrett-Connor E, Khaw KT \& Yen SS. Endogenous sex hormone levels in older adult men with diabetes mellitus. American Journal of Epidemiology 1990132 895-901. (https://doi.org/10.1093/ oxfordjournals.aje.a115732)

23 Laaksonen DE, Niskanen L, Punnonen K, Nyyssönen K, Tuomainen TP, Valkonen VP, Salonen R \& Salonen JT. Testosterone and sex hormone-binding globulin predict the metabolic syndrome and diabetes in middle-aged men. Diabetes Care 200427 1036-1041. (https://doi.org/10.2337/diacare.27.5.1036)

24 Dhindsa S, Miller MG, McWhirter CL, Mager DE, Ghanim H, Chaudhuri A \& Dandona P. Testosterone concentrations in diabetic and nondiabetic obese men. Diabetes Care 201033 1186-1192. (https://doi.org/10.2337/dc09-1649)

25 Brand JS, van der Tweel I, Grobbee DE, Emmelot-Vonk MH \& van der Schouw YT. Testosterone, sex hormone-binding globulin and the metabolic syndrome: a systematic review and meta-analysis of observational studies. International Journal of Epidemiology 201140 189-207. (https://doi.org/10.1093/ije/dyq158)

26 Yao QM, Wang B, An XF, Zhang JA \& Ding L. Testosterone level and risk of type 2 diabetes in men: a systematic review and meta-analysis. Endocrine Connections 20187 220-231. (https://doi.org/10.1530/ EC-17-0253)

27 Al Hayek AA, Khader YS, Jafal S, Khawaja N, Robert AA \& Ajlouni K. Prevalence of low testosterone levels in men with type 2 diabetes mellitus: a cross-sectional study. Journal of Family and Community Medicine 201320 179-186. (https://doi.org/10.4103/2230$8229.122006)$

28 Elabbady A, Hashad MM, Kotb AF \& Ghanem AE. Studying the effect of type 2 diabetes mellitus on prostate-related parameters: a prospective single institutional study. Prostate International 20164 156-159. (https://doi.org/10.1016/j.prnil.2016.07.005)

29 Corona G, Monami M, Rastrelli G, Aversa A, Sforza A, Lenzi A, Forti G, Mannucci E \& Maggi M. Type 2 diabetes mellitus and testosterone: a meta-analysis study. International Journal of Andrology 201134 528-540. (https://doi.org/10.1111/j.13652605.2010.01117.x)

30 Tomar R, Dhindsa S, Chaudhuri A, Mohanty P, Garg R \& Dandona P. Contrasting testosterone concentrations in type 1 and type 2 diabetes. Diabetes Care 200629 1120-112. (https://doi.org/10.2337/ dc06-0197)

31 Dhindsa S, Prabhakar S, Sethi M, Bandyopadhyay A, Chaudhuri A $\&$ Dandona P. Frequent occurrence of hypogonadotropic hypogonadism in type 2 diabetes. Journal of Clinical Endocrinology and Metabolism 200489 5462-5468. (https://doi.org/10.1210/ jc.2004-0804)

32 Hong CY, Park JH, Ahn RS, Im SY, Choi HS, Soh J, Mellon SH \& Lee K. Molecular mechanism of suppression of testicular steroidogenesis by proinflammatory cytokine tumor necrosis factor alpha. Molecular and Cellular Biology 200424 2593-2604. (https://doi. org/10.1128/MCB.24.7.2593-2604.2004)

33 Watanobe $\mathrm{H} \&$ Hayakawa Y. Hypothalamic interleukin-1 beta and tumor necrosis factor-alpha, but not interleukin-6, mediate the endotoxin-induced suppression of the reproductive axis in rats. Endocrinology 2003144 4868-4875. (https://doi.org/10.1210/ en.2003-0644)

34 Laaksonen DE, Niskanen L, Punnonen K, Nyyssönen K, Tuomainen TP, Valkonen VP \& Salonen JT. The metabolic syndrome and smoking in relation to hypogonadism in middle-aged men: a prospective cohort study. Journal of Clinical Endocrinology and Metabolism 200590 712-719. (https://doi. org/10.1210/jc.2004-0970)

35 Yeap BB, Chubb SA, Hyde Z, Jamrozik K, Hankey GJ, Flicker L \& Norman PE. Lower serum testosterone is independently associated with insulin resistance in non-diabetic older men: the Health In Men Study. European Journal of Endocrinology 2009161 591-598. (https:// doi.org/10.1530/EJE-09-0348) 
36 Xia F, Xu X, Zhai H, Meng Y, Zhang H, Du S, Xu H, Wu H \& Lu Y. Castration-induced testosterone deficiency increases fasting glucose associated with hepatic and extra-hepatic insulin resistance in adult male rats. Reproductive Biology and Endocrinology 201311106. (https://doi.org/10.1186/1477-7827-11-106)

37 Grossmann M, Thomas MC, Panagiotopoulos S, Sharpe K, Macisaac RJ, Clarke S, Zajac JD \& Jerums G. Low testosterone levels are common and associated with insulin resistance in men with diabetes. Journal of Clinical Endocrinology and Metabolism 200893 1834-1840. (https://doi.org/10.1210/jc.2007-2177)

38 Brüning JC, Gautam D, Burks DJ, Gillette J, Schubert M, Orban PC, Klein R, Krone W, Müller-Wieland D \& Kahn CR. Role of brain insulin receptor in control of body weight and reproduction. Science 2000289 2122-2125.

39 Saylor PJ \& Smith MR. Metabolic complications of androgen deprivation therapy for prostate cancer. Journal of Urology 2013189 S34-S42. (https://doi.org/10.1016/j.juro.2012.11.017)

40 Alibhai Duong-Hua M, Sutradhar R, Fleshner NE, Warde P, Cheung AM \& Paszat L. Impact of androgen deprivation therapy on cardiovascular disease and diabetes. Journal of Clinical Oncology 2009 27 3452-3458. (https://doi.org/10.1200/JCO.2008.20.0923)

41 Tsai HT, Keating NL, Van Den Eeden SK, Haque R, CassidyBushrow AE, Ulcickas Yood M, Smith MR \& Potosky AL. Risk of diabetes among patients receiving primary androgen deprivation therapy for clinically localized prostate cancer. Journal of Urology 2015 193 1956-1962. (https://doi.org/10.1016/j.juro.2014.12.027)

42 Morford J \& Mauvais-Jarvis F. Sex differences in the effects of androgens acting in the central nervous system on metabolism. Dialogues in Clinical Neuroscience 201618 415-424.

43 Virtue S \& Vidal-Puig A. Adipose tissue expandability, lipotoxicity and the Metabolic Syndrome - an allostatic perspective. Biochimica et Biophysica Acta 20101801 338-349. (https://doi.org/10.1016/j. bbalip.2009.12.006)

44 Ibrahim MM. Subcutaneous and visceral adipose tissue: structural and functional differences. Obesity Reviews 201011 11-18. (https:// doi.org/10.1111/j.1467-789X.2009.00623.x)

45 Moghetti P, Tosi F, Castello R, Magnani CM, Negri C, Brun E, Furlani L, Caputo $\mathrm{M} \&$ Muggeo $\mathrm{M}$. The insulin resistance in women with hyperandrogenism is partially reversed by antiandrogen treatment: evidence that androgens impair insulin action in women Journal of Clinical Endocrinology and Metabolism 199681 952-960.

46 Gambineri A, Patton L, Vaccina A, Cacciari M, Morselli-Labate AM, Cavazza C, Pagotto U \& Pasquali R. Treatment with flutamide, metformin, and their combination added to a hypocaloric diet in overweight-obese women with polycystic ovary syndrome: a randomized, 12-month, placebo-controlled study. Journal of Clinical Endocrinology and Metabolism 200691 3970-3980. (https://doi. org/10.1210/jc.2005-2250)

47 Pasquali R, Gambineri A, Anconetani B, Vicennati V, Colitta D, Caramelli E, Casimirri F \& Morselli-Labate AM. The natural history of the metabolic syndrome in young women with the polycystic ovary syndrome and the effect of long-term oestrogen-progestagen treatment. Clinical Endocrinology 199950 517-527. (https://doi. org/10.1046/j.1365-2265.1999.00701.x)

48 Dhindsa S, Ghanim H, Batra M, Kuhadiya ND, Abuaysheh S, Sandhu S, Green K, Makdissi A, Hejna J, Chaudhuri A, et al. Insulin resistance and inflammation in hypogonadotropic hypogonadism and their reduction after testosterone replacement in men with type 2 diabetes. Diabetes Care 201639 82-91. (https://doi.org/10.2337/dc15-1518)
49 Shigehara K, Konaka H, Kato Y, Iijima M, Nakashima K, Kawaguchi S, Nohara T, Izumi K, Namiki M \& Mizokami A. Effect of testosterone replacement therapy on sexual function and glycemic control among hypogonadal men with type 2 diabetes mellitus. International Journal of Impotence Research 2018 [epub]. (https://doi.org/10.1038/s41443018-0065-z)

50 Canguven O, Talib RA, El Ansari W, Yassin DJ, Salman M $\&$ Al-Ansari A. Testosterone therapy has positive effects on anthropometric measures, metabolic syndrome components (obesity, lipid profile, Diabetes Mellitus control), blood indices, liver enzymes, and prostate health indicators in elderly hypogonadal men. Andrologia 201749 [epub]. (https://doi.org/10.1111/and.12768)

51 Fink J, Matsumoto M \& Tamura Y. Potential application of testosterone replacement therapy as treatment for obesity and type 2 diabetes in men. Steroids 2018138 161-166. (https://doi. org/10.1016/j.steroids.2018.08.002)

52 Gianatti EJ, Dupuis P, Hoermann R, Strauss BJ, Wentworth JM, Zajac JD, Grossmann M. Effect of testosterone treatment on glucose metabolism in men with type 2 diabetes: a randomized controlled trial. Diabetes Care 201437 2098-2107. (https://doi.org/10.2337/dc13-2845)

53 Grossmann M, Hoermann R, Wittert G \& Yeap BB. Effects of testosterone treatment on glucose metabolism and symptoms in men with type 2 diabetes and the metabolic syndrome: a systematic review and meta-analysis of randomized controlled clinical trials. Clinical Endocrinology 201583 344-351. (https://doi.org/10.1111/ cen.12664)

54 Azad N, Sakla N \& Bahn G. The effect of testosterone replacement therapy on glycemic control in hypogonadal men with type 2 diabetes mellitus. Journal of Clinical Diabetes 2018 1 1-5.

$55 \mathrm{Pal} \mathrm{M} \&$ Gupta S. Testosterone supplementation improves glucose homeostasis despite increasing hepatic insulin resistance in male mouse model of type 2 diabetes mellitus. Nutrition and Diabetes 2016 6 e236. (https://doi.org/10.1038/nutd.2016.45)

56 Bhasin S, Brito JP, Cunningham GR, Hayes FJ, Hodis HN, Matsumoto AM, Snyder PJ, Swerdloff RS, Wu FC, Yialamas MA. Testosterone therapy in men with hypogonadism: an Endocrine Society Clinical Practice Guideline. Journal of Clinical Endocrinology and Metabolism 2018103 1715-1744. (https://doi.org/10.1210/jc.2018-00229)

57 Grossmann M, Matsumoto AM. A perspective on middle-aged and older men with functional hypogonadism: focus on holistic management. Journal of Clinical Endocrinology and Metabolism 2017 102 1067-1075. (https://doi.org/10.1210/jc.2016-3580)

58 Guay AT, Jacobson J, Perez JB, Hodge MB, Velasquez E. Clomiphene increases free testosterone levels in men with both secondary hypogonadism and erectile dysfunction: who does and does not benefit? International Journal of Impotence Research 200315 156-165. (https://doi.org/10.1038/sj.ijir.3900981)

59 Pelusi C, Giagulli VA, Baccini M, Fanelli F, Mezzullo M, Fazzini A, Bianchi N, Carbone MD, De Pergola G, Mastroroberto M, et al. Clomiphene citrate effect in obese men with low serum testosterone treated with metformin due to dysmetabolic disorders: a randomized, double-blind, placebo-controlled study. PLoS ONE 201712 e0183369. (https://doi.org/10.1371/journal.pone.0183369)

60 Soares AH, Horie NC, Chiang LAP, Caramelli B, Matheus MG, Campos AH, Marti LC, Rocha FA, Mancini MC, Costa EMF, et al. Effects of clomiphene citrate on male obesity-associated hypogonadism: a randomized, double-blind, placebo-controlled study. International Journal of Obesity 201842 953-963. (https://doi. org/10.1038/s41366-018-0105-2)

Received in final form 7 December 2018 Accepted 10 December 2018

Accepted Preprint published online 10 December 2018 https://ec.bioscientifica.com https://doi.org/10.1530/EC-18-0450
(C) 2019 The authors Published by Bioscientifica Ltd
This work is licensed under a Creative Commons Attribution-NonCommercial-NoDerivatives 4.0 International License. 